\title{
Relocation of habituated black bears in the Klamath Mountains of California: an adaptive management case study
}

\author{
ROBERT J. SCHAEFER*1, DENNIS MOYLES², STEVEN MCDON- \\ ALD $^{1}$, MONTY CERVELLI ${ }^{1}$, AND DANIEL BECK ${ }^{1}$ \\ ${ }^{1}$ California Department of Fish and Wildlife, 1625 S. Main, Yreka, CA 96097, USA \\ ${ }^{2}$ Siskiyou County Department of Agriculture, Predatory Animal Control Specialist, 525 S. \\ Foothill Drive, Yreka, CA 96097, USA
}

*Corresponding Author: cervusphile@gmail.com

\begin{abstract}
Black bear (Ursus americanus) populations in California have increased in abundance and distribution despite rising trends in the urban encroachment of wildlands. As human-black bear conflicts increase, opportunities to study the relocation of black bears in an adaptive management setting are important for improving the management of this highprofile species. Habituated black bears, some tamed and made tractable through human-controlled food conditioning, were relocated to a remote region of the Klamath Mountains to analyze home range use, survival, return rates, and mortality. Relocated black bears with known outcomes demonstrated an $80 \%$ return rate, with $55 \%$ not surviving beyond five months. Female bears established home ranges significantly larger than males, and may suggest an enhanced maternal instinct in search of similar nutritional conditions prior to relocation. This study showed that the relocation of food-conditioned black bears resulted in high return rates, poor survival, and risk to public safety.
\end{abstract}

Key words: habituated, home range, Klamath Mountains, public safety, relocation, return rate, survival, telemetry, tractable, Ursus americanus

Black bear (Ursus americanus) populations in California have increased in abundance and distribution despite rising trends in the urban encroachment of wildlands (CDFW 2016; RJS, personal observation). With California's human population projected to reach 51 million by 2060 (PPIC 2018), the potential for increase in human-black bear conflicts is anticipated (Spencer et al. 2007). As a public trust wildlife agency, the California Department of Fish and Wildlife (CDFW) is responsible for the management of black bears. Human dimensions factors, such as strong public emotions and sociopolitical influences, can play a major role in the conflict mitigation of these charismatic carnivores (Manfredo and Dayer 2004). 
Human-black bear conflict is commonly associated with the concentration of anthropogenic food resources available to wildlife. Habituation is the term often applied to black bears in close proximity to humans and is defined as a decreased responsiveness to a stimulus with repeated presentation (Blumstein 2016). Habituation has been distinguished from tolerance, which is the intensity of disturbance that an individual tolerates without responding in a defined way, but both terms are commonly interchanged (Nisbet 2000). Human-controlled food conditioning differs from habituation or tolerance in that it shapes a black bears behavior through positive reinforcement (food reward) and can lead to an attraction to humans. In these cases, black bears can become tamed and tractable, protective of humans, and lose denning instincts (Caton 1886; Beckman and Berger 2003; Vickery and Mason 2003). Labeling a bear as habituated because it displays tolerance towards people can be a misuse of the term, premature, or inaccurate, and may curtail further inquiry into the causes behind this behavior (Smith et al. 2005). To facilitate a science-based management approach for habituated black bears, managers should clearly distinguish between the differences and causal mechanisms in the habituated behaviors when setting management objectives (Gunther et al. 2004).

Preventing black bears from becoming conditioned to human food sources is the foundation of most bear management programs (Spencer et al. 2007). Evaluating the outcome of policies governing how human-black bear conflicts are managed is important (Beckmann and Lackey 2004). Relocation is a non-lethal black bear management tool where the post-relocation homing instincts of these highly mobile large carnivores is well documented (Beckmann and Lackey 2004; Landriault et al. 2009). It has been suggested that the post-relocation homing success displayed by adult animals is a consequence of increased navigational ability gained by experience and fidelity to established home ranges (Rogers 1986; Landriault et al. 2006). However, in extreme cases of habituation when food conditioning has eroded the natural behaviors of black bears, the effects on homing instincts are less understood (Vickery and Mason 2003; Herrero et al. 2005).

Adaptive wildlife management seeks to improve the integration of science and management by focusing decision-making on hypothesis-testing and structuring management actions as field experiments (Enck et al. 2006). This can allow shared learning among scientists, managers, and stakeholders and can provide integrated approaches when resolving difficult wildlife management issues (Lee 1999; Spencer et al. 2007). In California, where policies generally prevent the relocation of habituated black bears, research opportunities describing the behavioral details and outcomes when relocation is used are rare. Although most the public prefers non-lethality when resolving human-black bear conflict, killing the offending animal is still required for protecting public safety and property from depredating wildlife.

We discovered a unique and illegal wildlife feeding violation at a remote private residence in the Klamath Mountains of northwestern California. Wild black bears had been under the influence of human-controlled food conditioning for $>20$ years where many of the black bears had become tamed and tractable, were cohabitating with humans, and presenting significant conflict and safety issues with nearby landowners and the public. The relocation of these black bears presented an opportunity to collect and analyze quantitative data for managing human-black bear conflict where human-controlled food conditioning has been used. 


\section{METHODS}

\section{Study Area}

The Klamath Mountains are some of the most rugged and topographically diverse ranges in California (Fig. 1). With steep mountain peaks exceeding $2500 \mathrm{~m}$ separated by low lying river valleys, it remains one of the most pristine and least populated regions in California. The World Conservation Union (CDFG 2007) recognizes these ranges for their biological diversity and as an area of botanical significance. The study area includes federal Wilderness Areas, culturally important tribal lands, and a climate that varies considerably with more rainfall than any other part of the state where heavy snowfall is contrasted by summer temperatures often exceeding $37^{\circ} \mathrm{C}$.

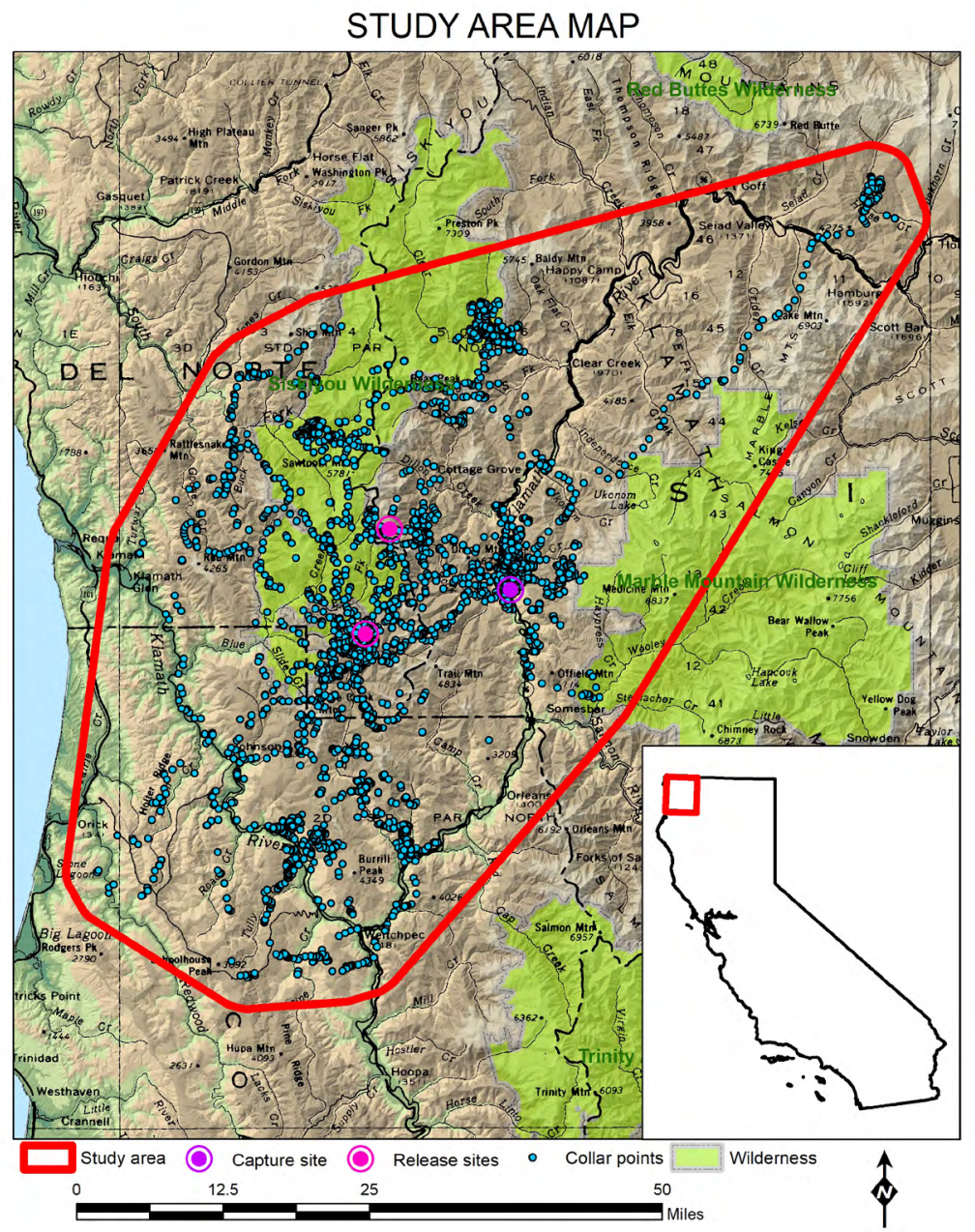

Figure 1. Study area in northwestern California showing capture and release sites and satellite locations for 8 relocated black bears. 
These moist inland forests are dominated by conifer species including Douglas fir (Pseudotsuga menziesii), ponderosa pine (Pinus ponderosa), and sugar pine (Pinus lambertiana), with high elevation sub-alpine forests consisting primarily of white fir (Abies concolor), red fir (Abies magnifica), western white pine (Pinus monticola) and mountain hemlock (Tsuga mertensiana). Black oak (Quercus velutina) and white oak (Quercus alba) forests can be found at lower elevations with related species including tan oak (Lithocarpus densiflorus) and chinkapin oak (Quercus muehlenbergii) also present. Where shrubs are interspersed, they may include huckleberry (Vaccinium ovatum), manzanita (Arctostaphylos klamathensis), Ceanothus sp. and Prunus sp.

The rich fauna of the region contains a complement of terrestrial predators commonly represented by the black bear (Ursus americanus), mountain lion (Puma concolor), coyote (Canis latrans) bobcat (Lynx rufus), and gray fox (Urocyon cinereoargenteus). Native ungulates including the Roosevelt elk (Cervus canadensis roosevelti) and black-tailed deer (Odocoileus hemionus) occur throughout the area, with special status mammal and bird species highlighted by the fisher (Pekania pennanti), American marten (Martes americana), northern spotted owl (Strix occidentalis caurina) and northern goshawk (Accipiter gentilis). The low-lying river valleys drain the Klamath River watershed where sharp declines in fish populations have led to special status listings for several of these species.

\section{Capture, Marking, and Monitoring}

We captured black bears with baited culvert traps within $50 \mathrm{~m}$ of where the illegal feeding was occurring using methods prescribed by the CDFW Wildlife Investigations Lab (CDFW 2012). Captured bears were immobilized with combinations of telazol ${ }^{\circledR}$ and medetomidine, with one individual receiving butorphanol tartrate, azaperone tartrate and medetomidine hydrochloride (BAM $\left.{ }^{\circledR}\right)$. We physically examined bears, monitored vital rates, determined sex and weight, estimated ages (Heffelfinger 1997), and applied ear tags showing an identification number and non-consumption warning label. A body condition score was estimated for each bear using a one (lowest) to four (highest) scale based on the average of bone prominence scores measured at 5 locations (Noyce et al., 2002). We attached a satellite telemetry collar (Vectronics ${ }^{\circledR}$ ) with $\sim 9$ months of battery life to randomly selected bears that provided hourly GPS locations and mortality notifications. Bears were transported under anesthesia to a highly remote and inaccessible release point $\sim 30 \mathrm{~km}$ from the capture site where they were removed from traps, anesthesia reversed, and monitored until ambulatory. Recaptured and injured black bears were humanely euthanized according to capture protocols and methods described by the WIL (CDFW 2012).

We monitored the mortality status, return rate, and home range use of collared black bears with ground telemetry and with satellite locations until the collars stopped transmitting. When a mortality occurred, we investigated within 48 hours when feasible and evaluated for a cause-specific death (Schaefer et al. 2000, Bender et al. 2004). A relocated black bear was considered "returned" when it was recaptured, observed, or photographed near the capture site, detected with ground telemetry, or satellite locations showed movements within $4 \mathrm{~km}$ of the capture site. Survival was determined as the number of days a black bear was known to survive after relocation. Outcomes could be determined for collared black bears by monitoring their status during the lifetime of the collar, or for non-collared black bears by ear tag number when recaptured, observations post relocation, or by remote cameras monitored near the capture site. 


\section{Home Range and Statistical Analysis}

We used ArcMap (ESRI, Redlands, CA) to create a minimum convex polygon around all satellite locations for individual black bears which uses a convex hull to estimate home range size. Due to the long distances moved quickly by many collared black bears and the short duration some bears were alive, this allowed us to examine the extent of a black bears movements. For statistical comparisons between sexes, we used a 2-sample t-test (95\% CI) to determine differences in home range size for collared black bears, and for survival days of relocated black bears with known outcomes.

\section{RESULTS}

We captured seventeen black bears (10 males and 7 females) during 11 trap nights between 7 August 2017 and 20 October 2017 ranging in weight from 20-204k (mean = $126 \mathrm{k}$ ) (Table 1). Among captured black bears, 13 were relocated, three were euthanized due to injuries from other bears, and one released at the capture site due to weather issues. All relocated black bears were ear tagged and eight animals ( 4 males and 4 females) were equipped with satellite telemetry collars.

For relocated black bears where outcomes could be determined, $80 \%$ ( 8 of 10 ) returned to the capture site within 23 days (mean $=8.5$; range $3-23$ ), and 55\% (5 of 9) died within 140 days post relocation (mean $=79.6$; range $51-140$ ). Two collared black bear mortalities could be investigated promptly showing only evidence of weight loss as a possible cause of death. There was no difference in survival between sexes $(\mathrm{P}>0.05)$, but female homeranges $\left(\right.$ mean $\left.=1106.15 \mathrm{~km}^{2}\right)$ were significantly larger than males $\left(\right.$ mean $=197.63 \mathrm{~km}^{2} ; \mathrm{t}$ $=-9.501, \mathrm{df}=3, \mathrm{P}=0.0003)$.

\section{DISCUSSION}

Relocation is an ineffective management tool for reducing food-conditioned black bear conflict, as evidenced by the high mortality and return rate of relocated bears (Rogers 1986; Hopkins and Kalinowski 2013). Many black bears traversed some of the most challenging terrain in California to return within a few days to the capture site. Moreover, return rates were likely underestimated as the outcomes for 3 non-collared black bears could not be determined and reports of two ear tagged black bears killed by nearby landowners for safety reasons could not be confirmed. Some studies have suggested that as relocation distances increase, return rates may decline (Laundrialt et al. 2009; Rogers 1986). In this study black bears were captured in a sparsely populated and highly remote area adjacent to a federal wilderness area and moved to some of the most inaccessible terrains in northern California. Due to the remoteness of this area, attempting to increase the relocation distance would have resulted in extensive and potentially unsafe transport times and closer proximity to human population centers.

The survival of relocated black bears was remarkably low as most with known outcomes did not survive beyond 140 days. For two collared black bear deaths that could be investigated promptly, a dramatic decline in observed body weight was the only factor found to be associated with death. These black bears died at 51- and 67-days post-relocation and were found with no obvious signs of physical trauma, injury or disease but with significant declines observed in body condition. Both animals were in excellent nutritional condition at the time of capture and relocated to habitats ideal for black bears. The human-controlled food 
Table 1. Biological characteristics, survival, return rate, home range estimates, and outcomes for 17 collared and non-collared black bears captured and relocated during 11 trap nights near Somes Bar, California from 12 August 2017 through 19 October 2017.

\begin{tabular}{|c|c|c|c|c|c|c|c|c|}
\hline ID\# & Age & $\begin{array}{l}\text { Weight } \\
(\mathrm{kg})\end{array}$ & Sex & $\begin{array}{l}\text { Days } \\
\text { Until } \\
\text { Return }\end{array}$ & $\begin{array}{l}\text { Days } \\
\text { Alive }\end{array}$ & $\begin{array}{l}\text { Home } \\
\text { Range } \\
\mathrm{km}^{2}\end{array}$ & $\mathrm{BCS}^{*}$ & Outcome \\
\hline \multicolumn{9}{|c|}{ Collared Bears } \\
\hline 111 & $5-7$ & 136 & M & 3 & 68 & 94.68 & 4 & Recapture/euthanize \\
\hline 114 & $6-9$ & 158 & $\mathrm{M}$ & 5 & 67 & 291.81 & 4 & Mortality/poor nutrition \\
\hline 103 & $3-5$ & $77 * *$ & $\mathrm{~F}$ & 8 & na & 888.70 & 3 & Stopped transmitting/267 days \\
\hline 110 & $6-9$ & 204 & $\mathrm{~F}$ & 23 & na & 1234.2 & 4 & Stopped transmitting/274 days \\
\hline 112 & $6-9$ & 181 & $\mathrm{~F}$ & $\mathrm{nr}$ & 140 & 1258.95 & 4 & Killed by public \\
\hline 108 & 12 & $163 * *$ & M & 8 & 51 & 145.97 & 4 & Mortality/poor nutrition \\
\hline 107 & $6-9$ & 158 & $\mathrm{M}$ & $\mathrm{nr}$ & na & 258.09 & 4 & Stopped transmitting/175 days \\
\hline 106 & $6-9$ & 113 & $\mathrm{~F}$ & 4 & na & 1042.72 & 3 & Stopped transmitting/62 days \\
\hline \multicolumn{9}{|c|}{ Non-collared Bears } \\
\hline 512 & $5-8$ & 90 & $\mathrm{~F}$ & 11 & na & na & 3 & Killed by public \\
\hline 373 & $5-8$ & 136 & $\mathrm{~F}$ & 9 & 72 & na & 4 & Recapture/euthanize \\
\hline NA & $6-9$ & 204 & M & na & na & na & 4 & Euthanized due to injury \\
\hline 105 & $3-5$ & 90 & $\mathrm{M}$ & na & na & na & 3 & Unknown \\
\hline NA & 1 & $20 * *$ & M & na & na & na & 1 & Euthanized due to injury \\
\hline 102 & $6-9$ & 181 & $\mathrm{M}$ & na & na & na & 4 & Unknown \\
\hline 113 & $3-5$ & 136 & $\mathrm{M}$ & na & na & na & 4 & Released at capture site \\
\hline 109 & 2 & 57 & M & na & na & na & 2 & Unknown \\
\hline NA & $3-5$ & 45 & $\mathrm{~F}$ & na & na & na & 2 & Euthanized due to injury \\
\hline
\end{tabular}

* $\mathrm{BCS}=$ Body Condition Score

$* *=$ Actual Weight

$\mathrm{nr}=$ No Return

na $=$ Not available

conditioning experienced by these black bears may have led to a loss of natural behaviors and inability to adapt to fluctuating conditions that reduced their survival in the wild (Stiver et al. 1997; Vickery and Mason 2003).

Home range results were difficult to interpret due to small sample size and the inability to quantify a level of habituation for individual black bears. Alt et al. (1980) and others found that among wild bears, males maintain home ranges about 4 times larger than females. Beckmann and Berger (2003) showed that urban black bears had significantly smaller home ranges in comparison to non-urban individuals. Pop et al. (2012) suggested that home range sizes were strongly affected by the previous experience of the individual bear with humans, and found that habituated bears that are relocated will first explore the unknown release site prior to dispersing to their former home range. It has also been hypothesized that adult females benefit from a strong desire to return to their established home range where they have been able to meet the nutritional requirements necessary for reproduction (Rogers 1976; 
Elowe and Dodge 1989). The extensive home ranges quickly established by females in this study were likely influenced by human-controlled food conditioning, relocation to unfamiliar environments, and a search for similar food conditioned circumstances prior to release.

The injuries for three black bears discovered upon capture were severe and consistent with bite wounds between conspecifics. When initially approaching the residence where the long-term feeding had occurred, 11 black bears could be observed at the residence behaving in a tamed and tractable manner (Fig. 2). During this period there were significant increases in public safety issues also being reported by adjacent landowners and motorists on the nearby highway for black bears attracted to humans (Fig. 3). Bears are considered the least social group among the carnivores (Gittleman 1989).Intraspecific killing has been well documented (Garshelis 1994), where several general factors driving aggression between conspecifics include population regulation, dominance disputes, and reproductive advantage (Amstrup et al. 2006). In this situation, the concentration of black bears resulting from decades of human-controlled food conditioning likely resulted in unknown rates of intraspecific aggression and mortality. It is also worth noting that the primary individual responsible for the food conditioning of these black bears had visible bear induced injuries and scars to their arms (personal observations RJS, DM, SM, MC).

A female black bear that displayed docility in the trap had lost a front leg near the shoulder joint and walked on three legs, but the injury was healed, and she was collared and relocated. This bear did not return to the capture site but established a home range of 1234.25 $\mathrm{km}^{2}$ in 140 days post relocation before being killed by the public for entering a structure. This remarkable journey across major rivers and terrain with only 3 legs is a testament to a black bears ability to survive, but also suggest a search for similar habitat conditions and food availability (Fig. 4).

CDFW black bear policy states that habituated black bears are not candidates for relocation and will be either humanely euthanized or placed in a permitted animal care facility (CDFW 2019). The decision to relocate these black bears provided the rare opportunity to study relocation behavior in food conditioned black bears, but it also exposed the risk of this technique as an acceptable management option.

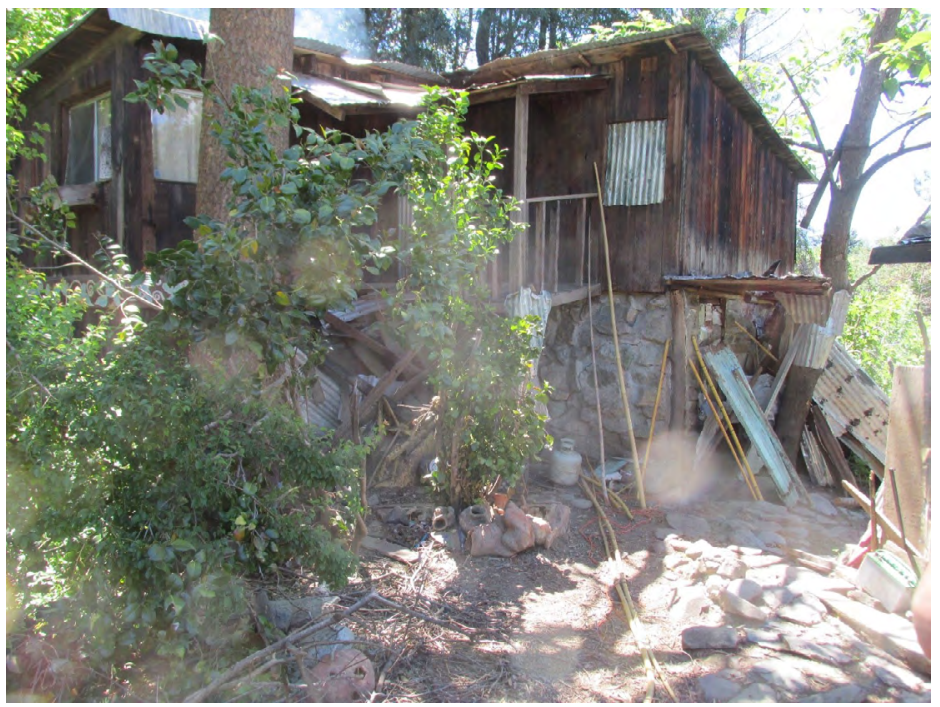

Figure 2. Residence in northwestern California where human-controlled food conditioning of black bears occurred for $>20$ years. Photo Credit: R. Schaefer 


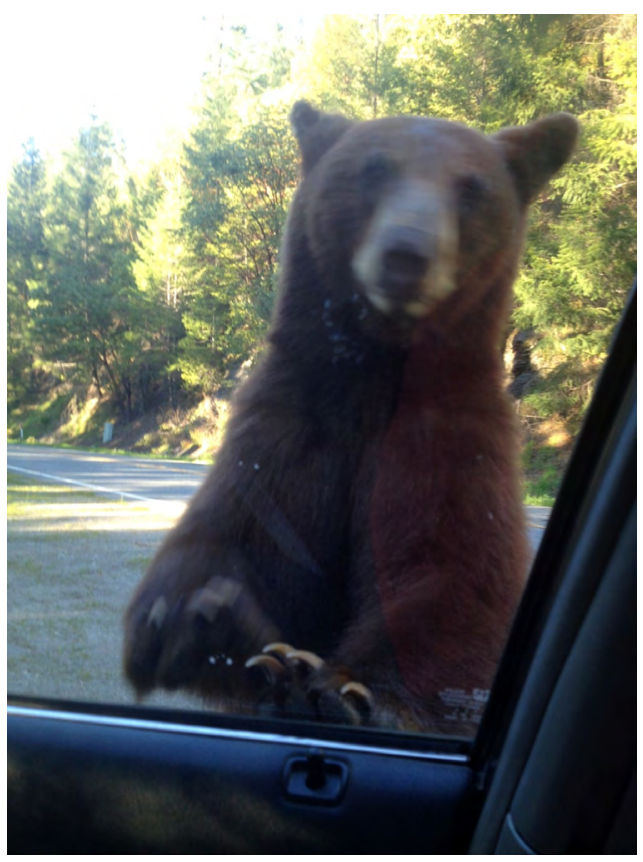

Figure 3. Photo taken by unsuspecting motorist when stopped on highway 96 in Siskiyou County for a lunch break near the residence where the human-controlled food conditioning occurred. Photo Credit: S. Schaefer

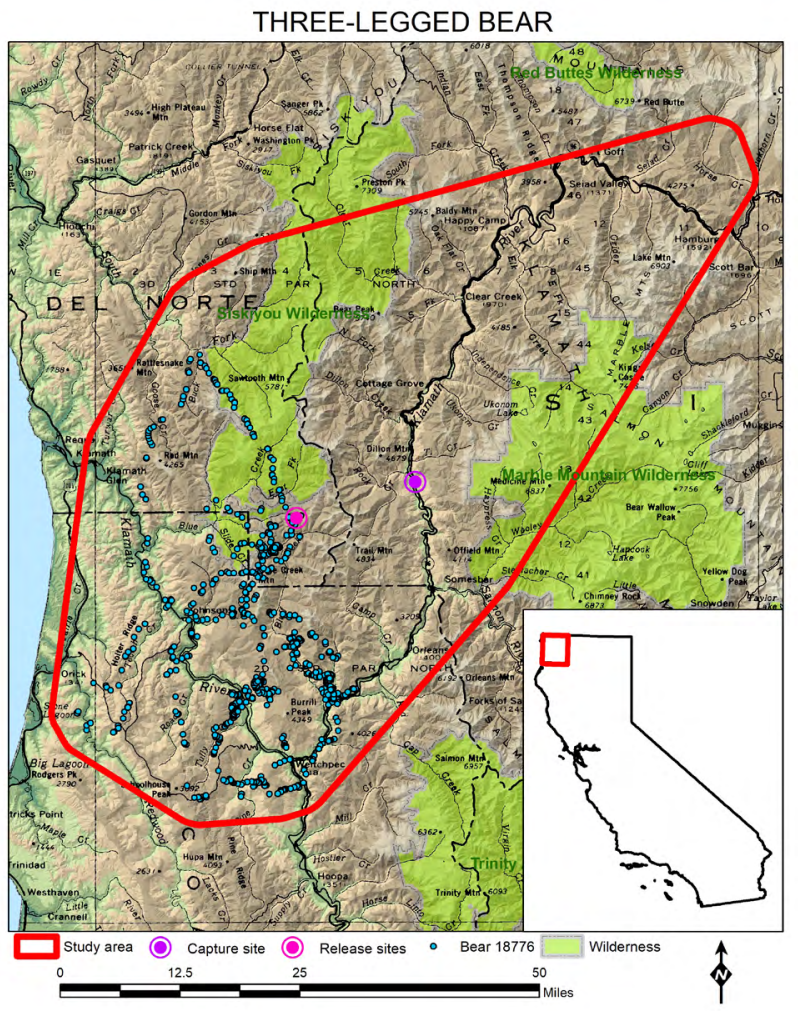

Figure 4. Satellite locations showing the extensive movements of a food conditioned 3-legged black bear that was killed by the public after 140 days post-relocation in the Klamath Mountains of northwestern California. 
We propose that compassion without reason can result in cruelty without guilt, and encourage managers to consider this case study when facing similar decisions in the future. Bath (1998) postulated that the public should not dictate wildlife policy, or wildlife management actions. Whether for endangered species protection, public safety, or human-wildlife conflict, the human dimensions of wildlife management requires agencies to bridge the public's trust when lethal actions are advised (Schaefer et al. 2000; Talbert et al. 2020). This requires leadership capable of articulating the consequences or potential risks facing humans and wildlife in modern society when difficult decisions may be required. In this instance, relocation failed to resolve this difficult human-black bear conflict humanely and with public safety as a primary concern.

\section{ACKNOWLEDGMENTS}

We thank J. Courtney for cooperation and access to private property, and the staff at Mount Shasta Fish Hatchery for their helpful assistance with baiting supplies. S. Schaefer, T. Schaefer, G. Plank, F. Schmalenberger, and 3 anonymous reviewers provided helpful discussions and comments on the manuscript. This is a contribution from the hunter-conservationists of California, and the Law Enforcement Division of the California Department of Fish and Wildlife.

\section{LITERATURE CITED}

Alt, G. L., G. Matula, F. Alt, and J. Lindzey. 1980. Dynamics of home range and movements of adult black bears in northeastern Pennsylvania. International Conference on Bear Research and Management 4:131-136.

Amstrup, S. C., I. Stirling, T. Smith, C. Perham, and G. Thiemann. 2006. Recent observations of intraspecific predation and cannibalism among polar bears in the southern Beaufort Sea. Polar Biology 29:997-1002.

Bath, A. J. 1998. The role of human dimensions in wildlife resource research in wildlife management. Ursus 10:349-355.

Beckmann, J. P., and J. Berger. 2003. Rapid ecological and behavioural changes in carnivores: the responses of black bears (Ursus americanus) to altered food. Journal of Zoology, London 261:207-212.

Beckmann, J. P., and C. W. Lackey. 2004. Are desert basins effective barriers to movements of relocated black bears (Ursus americanus)? Western North American Naturalist 64:269-272.

Bender, L. C., G. Schirato, R. Spencer, K, Mcallister, and B. Murphie. 2004. Survival, cause-specific mortality, and harvesting of black-tailed deer in Washington. Journal of Wildlife Management 68:870-878.

Blumstein, D. T. 2016. Habituation and sensitization: new thoughts about old ideas. Animal Behavior 120:255-262.

California Department of Fish and Game (CDFG). 2007. California's Wildlife Action Plan. Prepared by Wildlife Health Center, School of Veterinary Medicine, University of California, Davis, USA.

California Department of Fish and Wildlife (CDFW). 2012. Wildlife Restraint Handbook. 10th edition. Wildlife Investigations Lab, Rancho Cordova, CA, USA.

California Department of Fish and Wildlife (CDFW). 2016. Black bear population infor- 
mation. Available from: https:/www.wildlife.ca.gov/Conservation/Mammals/ Black-Bear/Population (February 2018)

California Department of Fish and Wildlife (CDFW). 2019. Statewide Black Bear Policy \#2071. Available from: https://wildlife.ca.gov/Conservation/Mammals/BlackBear/Statewide-Policy\#312501086-ii-response-categories-and-remedial-actions (February 2019)

Caton, J. 1886. Domestication of the grizzly bear. The American Naturalist 20:434-438.

Elowe, K. D., and W. E. Dodge. 1989. Factors affecting black bear reproductive success and cub survival. Journal of Wildlife Management 53:962-968.

Enck, J., D. Decker, S. Riley, J. Organ, L. Carpenter, and W. Siemer. 2006. Integrating ecological and human dimensions in adaptive management of wildlife-related impacts. Wildlife Society Bulletin 34:698-705.

Garshelis, D. L. 1994. Density-dependent population regulation of black bears. Pages 3-14 in M. Taylor, editor. Density-dependent Population Regulation in Black, Brown, and Polar Bears. International Conference on Bear Research and Management, Monograph Series 3.

Gittleman, J. L. 1989. Carnivore group living: comparative trends. Pages 183-207 in J. L. Gittleman, editor. Carnivore Behavior, Ecology and Evolution. Cornell University Press, Ithaca, NY, USA.

Gunther, A. K., K. Tonnessen, P. Dratch, and C. Servheen. 2004. Management of habituated grizzly bears in North America: report from a workshop. Transaction of the 69th North American Wildlife and Natural Resources Conference, Washington, D.C., USA.

Heffelfinger, J. 1997. Age criteria for Arizona game species. Special Report \#9. Arizona Game and Fish, Phoenix, AZ, USA.

Herrero, S., T. Smith, T. Debruyn, K. Gunther, and C. Matt. 2005. Brown bear habituation to people: safety, risks, and benefits. Wildlife Society Bulletin 33:362-371.

Hopkins, J. B., and S._Kalinowski. 2013. The fate of transported American black bears in Yosemite National Park. Ursus 24:120-126.

Landriault, L. J., M. Hall, J. Hamr, and F. Mallory. 2006. Long-range homing by an adult female Black Bear, Ursus americanus. Canadian Field-Naturalist 120:57-60.

Landriault, L. J., G. S. Brown, J. Hamr, and F. Mallory. 2009. Age, sex, and relocation distance as predictors of return for relocated nuisance black bears Ursus americanus in Ontario, Canada. Wildlife Biology 15:155-164.

Lee, K. N. 1999. Appraising adaptive management. Conservation Ecology 3:3-16.

Manfredo, M., and A. Dayer. 2004. Concepts for exploring the social aspects of humanwildlife conflict in a global context. Human Dimensions of Wildlife 9:317-328.

Nisbet, C. 2000. Disturbance, habituation, and management of waterbird colonies. Waterbirds 23:312-332.

Noyce, K.V., P. Coy, and D. Garshelis. 2002. Bone prominence and skin-fold thickness as predictors of body fat and reproduction in American black bears. Ursus 13:275284.

Pop, M. L., A. Sallay, L. Bereczky, and S.Chiriac. 2012. Land use and behavioral patterns of brown bears in the South-Eastern Romanian Carpathian Mountains: a case study of relocated and rehabilitated individuals. Procedia Environmental Sciences 14:111-122. 
Public Policy Institute of California (PPIC). 2018. California's Future: Population. Available from: http://www.ppic.org/publication/californias-future-population/ (February 2018)

Rogers, L. L. 1976. Effects of mast and berry crop failures on survival, growth, and reproductive success of black bears. Transactions for the Forty-First North American Wildlife Resources Conference 41:431-438.

Rogers, L. L. 1986. Effects of translocation distance on frequency of return by adult black bears. Wildlife Society Bulletin 14:76-80.

Stiver, H. M., M. R. Pelton, and C. D. Scott. 1997. Use of pen-reared black bears for augmentation or reintroductions. Bears: Their Biology and Management, Ninth International Conference on Bear Research and Management 9:145-150.

Schaefer, R. J., S. G. Torres, and V. C. Bleich. 2000. Survivorship and cause-specific mortality in sympatric populations of mountain sheep and mule deer. California Fish and Game 86:127-135.

Smith, T., S. Herrero, and T. Debruyn. 2005. Alaskan brown bears, humans, and habituation. Ursus 16:1-10.

Spencer, R. D., R. Beausoleil, and D. Martorello. 2007. How agencies respond to human-black bear conflicts: a survey of wildlife agencies in North America. Ursus 18:217-229.

Talbert, L., S. Leslie, and S. Black. 2020. Use of predator controls to address human wildlife conflict. International Journal of Avian and Wildlife Biology 5(1):9-13.

Vickery, S., and G. Mason. 2003. Behavioral persistence in captive bears: implications for reintroduction. Ursus 14:35-43.

Submitted 9 October 2020

Accepted 22 January 2021

Associate Editor was V. Monroe 